\title{
A Public Health Ethics Case for Mitigating Zoonotic Disease Risk in Food Production
}

\author{
Justin Bernstein ${ }^{1}$ (D) Jan Dutkiewicz ${ }^{2}$ \\ Accepted: 7 April 2021 / Published online: 8 May 2021 \\ (C) The Author(s), under exclusive licence to Springer Nature Switzerland AG 2021
}

\begin{abstract}
This article argues that governments in countries that currently permit intensive animal agriculture - especially but not exclusively high-income countries - are, in principle, morally justified in taking steps to restrict or even eliminate intensive animal agriculture to protect public health from the risk of zoonotic pandemics. Unlike many extant arguments for restricting, curtailing, or even eliminating intensive animal agriculture which focus on environmental harms, animal welfare, or the link between animal source food (ASF) consumption and noncommunicable disease, the argument in this article appeals to the value of protecting populations from future global health emergencies and their broad social, economic, and health impacts, taking the SARS-CoV-2 virus as a particularly salient example. The article begins by identifying how intensive animal agriculture contributes to the outbreak (and risk of future outbreaks) of zoonotic diseases. Next, we explore three specific policy options: 1. Incentivizing plant-based and cell-based ASF alternatives through government subsidies; 2. Disincentivizing intensive ASF production through the adoption of a "zoonotic tax"; and 3. Eliminating intensive ASF production through a total ban. We argue that all three of these measures are permissible, although we remain agnostic as to whether these measures are obligatory. We argue for this conclusion on the grounds that each measure is justified by the same sorts of considerations that justify other widely accepted public health interventions, and each is compatible with a variety of theories of justice. We then address potential objections. Finally, we discuss how our novel argument relates to extant ethical arguments in favor or curtailing ASF production and consumption.
\end{abstract}

Keywords Political philosophy · Public health ethics $\cdot$ COVID-19 $\cdot$ Animal agriculture $\cdot$ Zoonotic disease

Justin Bernstein

jubernstein@gmail.com

Jan Dutkiewicz

jan.dutkiewicz@gmail.com

Extended author information available on the last page of the article 


\section{Introduction}

Zoonotic diseases - those that can be transmitted from animals to humans and back again represent a major and growing threat to global public health. The global outbreak of SARSCoV-2, the virus that causes COVID-19, is a particularly impactful and visible case. Its total cost in terms of economic harm, illness, and mortality in the United States alone has been estimated at \$16 trillion (Cutler and Summers 2020). While there is no certainty about the cause of the outbreak, it was likely caused by the transmission of disease from wildlife to humans, either directly through contact or consumption, or through the intermediary of a farmed animal. It is also only the latest in a string of recent zoonotic outbreaks. Upwards of three-quarters of all emerging human pathologies are zoonotic in origin, and the majority of these have been linked to the intensification of agriculture (Jones et al. 2008). The globalization of trade and travel and the complexity of international supply chains have, in turn, made it much more likely that local outbreaks can turn into global crises with wide-ranging public health impacts. Meanwhile, modern medicine has not only failed to catch up to the zoonotic threat, but in some ways is losing ground, due in part to growing global antibiotic resistance. So, from a public health ethics perspective, we should assess measures aimed at mitigating zoonotic risks. This is especially the case with systemic, predictable sources of zoonotic risk such as agriculture and food production.

In this article, we highlight the role of intensive animal agriculture in public health emergencies such as the COVID-19 pandemic. We then argue that if governments are permitted to infringe on liberty to promote public health in similar cases, then this permission extends to these food production practices. Governments are justified in restricting or even eliminating the intensive production of animals in order to mitigate the risk of future zoonotic pandemics and their associated harms and costs. While much of our argument focuses on the United States, one could apply our arguments to the context of other countries, including both countries in the Global North where intensive agriculture is the norm as well as those countries in the Global South where animal agriculture is fast becoming intensive and industrialized, including major animal source food (ASF) producers such as Brazil and China.

We focus specifically on three supply-side policy options: a Pigouvian tax or "zoonotic tax" (Espinosa et al. 2020) on producers that would factor the cost of zoonotic disease risk into the price of ASF products, government subsidies for the development of plant-based or cell-based ASF alternatives that would replace ASF production, and an outright ban that would involve passing legislation that makes intensive animal production illegal. We then appeal to four different kinds of justifications for other public health measures to support these three kinds of kinds of policies: an appeal to producing overall benefits; solving collective action problems pertaining to health; preventing harm and protecting rights; and realizing principles of distributive justice. These four justifications are self-standing, and one could accept one without accepting the others - each is meant to be sufficient to support the conclusion that, at least in principle, governments are morally permitted to implement the relevant policies. While we focus on making the case for the permissibility of these measures, one could draw on our arguments to support the conclusion that governments are obligated to undertake some combination of these policies - on the assumption that governments that fail to do so violate an obligation to protect public health.

Throughout, we restrict our focus to addressing the role that intensive animal production plays in causing or contributing to the spread of zoonotic, infectious, communicable diseases like COVID-19. There is an extensive body of critique of intensive animal agriculture rooted 
in claims about animals' rights or welfare (Fischer 2019; Singer 1975; Regan 1983; Dunayer 2001; Palmer 2010; Gruen 2011), environmental harms (Tilman and Clark 2014; Springmann et al. 2016; Schlottmann and Sebo 2019), and impacts on public health, primarily in the form of diet-related non-communicable diseases (Simon 2013; Springmann et al. 2018; Stubbs et al. 2018). Indeed, policy recommendations for government interventions meant to regulate or reduce meat production and/or consumption are often framed specifically in terms of some or all of these impacts (Springmann et al. 2018; Godfray et al. 2018; Katare et al. 2020; Bonnet et al. 2020). We discuss in our conclusion how our analysis might overlap with and strengthen some of these claims. Our main argument, however, focuses exclusively on the relationship between intensive animal source food production and zoonotic disease risk.

Here it is worth noting four limitations to our inquiry. First, we focus exclusively on governments rather than, say, considering how citizens should try to change current production patterns. There are major ongoing debates about individual obligations in the face of massive collective action problems (e.g., Sinnott-Armstrong 2005), but such debates do not affect our arguments, which concern in-principle justifications for governments to intervene. Second, we focus on policies directed at producers of intensive animal agriculture rather than consumers. We do so in part to make our focus manageable, but also because we remain skeptical that merely focusing on altering the 'demand' side will be sufficient to address the relevant health risks. Third, we will proceed with the assumption that the policies we propose would be effective. That is, we assume that there will be compliance with the relevant laws, that they would not incentivize black markets, and so forth. We make this assumption because getting clear about the principled public health case for the goal of reducing or eliminating animal agriculture is important in its own right. Fully assessing particular measures and their likely effects in different contexts will have to wait until a later date. (For a similar assumption in debates about the ethics of cigarette bans, see Grill and Voigt 2016, 293). Fourth, while we suggest subsidies for ASF alternatives as one of our policy options, we do not defend a particular systemic alternative to current production practices. This is because there are many food system alternatives that would be preferable from the perspective of public health. However, sketching and defending any alternative - or any number of alternatives - to current practices is beyond the scope of this article.

We proceed as follows. First, we provide some background information on zoonotic disease, its links to intensive animal agriculture, and some of its public health consequences. Second, we argue that a broad range of public health ethics justifications for state intervention in the public health interest hold in the case of intensive animal agriculture. We draw on arguments for other public health interventions that appeal to promoting overall well-being, solving collective action problems, preventing harm or rights violations, and realizing principles of distributive justice. Third, we consider a few natural objections to these arguments. We conclude by situating our argument vis-a-vis broader ethical critiques of intensive animal agriculture.

\section{The Intensification of Agriculture and the Threat of Zoonotic Disease}

The risk of zoonotic disease is inherent in human relations to farmed animals. As early as the Neolithic period, the domestication of animals created novel human-animal interfaces that likely led to the development of diseases including measles and smallpox (Berson 2019). In the century since the global outbreak of Spanish Flu between 1918 and 1920, zoonotic disease 
has led to other major transnational outbreaks including HIV, Ebola, SARS, MERS, and H1N1 swine flu, among others. COVID-19 is the latest and most impactful zoonotic event of the modern era, but it will certainly not be the last.

Currently, over half of all existing human pathogens, and almost three-quarters of emerging infectious diseases, are zoonotic in nature (Jones et al. 2008). The growing speed and intensity of zoonotic spread is primarily driven by anthropogenic environmental change and the intensification of animal agriculture (Jones et al. 2013; Rohr et al. 2019). Broadly speaking, this plays out in three ways.

First, human encroachment on natural ecosystems previously unoccupied by humans or domesticated species creates novel "species assemblages" that allow pathogens the opportunity to find new host species (Jones et al. 2013). Often it is urbanization and agriculture that drive large-scale land-use change, threatening biodiversity and exposing humans, wildlife, and farmed animals to novel diseases (Patz et al. 2004; Daszak et al. 2000). Agricultural expansion is driven by a range of factors, but chief among these is the need to raise farmed animals and grow their feed. The "meatification" of agricultural value chains, marked by increasing economies-of-scale production and consumption (Weis 2013), including rapid expansion in Asia (Jakobsen and Hansen 2020), has created "unprecedented" numbers of new potential vectors of zoonotic infection ( $\mathrm{Pal}$ et al. 2013).

Second, the intensification of animal production itself increases the size and density of animal populations in production facilities, which can facilitate disease spread between animals and between animals and workers (Graham et al. 2008; Gilchrist et al. 2007). This coupled with low genetic diversity on confined animal feeding operations (CAFOs) creates conditions where both zoonotic and non-zoonotic diseases can spread more easily (Springbett et al. 2003). It is unlikely that on-farm transmission of this sort played a part in the COVID-19 outbreak, but this form of zoonotic transmission has led to other recent pandemics such as H1N1 swine flu. Moreover, intensive farming operations frequently engage in widespread use of antimicrobials as therapeutic and prophylactic tools or as growth stimulants (Gilchrist et al. 2007) which in turn stimulates the development of antimicrobial-resistant pathogens.

Third, the expansion and intensification of conventional animal agriculture creates new forms of subsistence-based animal consumption. In the case of COVID-19, the rise of intensive animal farming in China in the final decades of the last millennium disrupted a smallholder farmer-based rural economy, pushing many former farmers to enter either the legal or illegal wildlife trade to make ends meet and to meet growing demand for these products (Schneider 2017). It is possible that such animals, brought to urban "wet markets" for consumption or having transferred zoonoses to more commonly farmed and consumed animal species, were the source of the SARS-CoV-2 outbreak.

The threat of a pandemic like COVID-19 has been recognized for a long time by epidemiologists and public health scholars, who have long called for closer attention to the link between intensive animal agriculture and zoonoses. In the wake of the SARS outbreak in 2002-2004, there were warnings of an impending "catastrophic storm of microbial threats," (Smolinski et al. 2003) including the risk presented by "an influenza or severe respiratory syndrome epidemic." (Benatar 2007) Less than a decade later the United Nations Environment Program warned of the potential public health impact of zoonoses caused by the "Livestock Revolution paradigm" of food production, especially in developing countries (UNEP 2016). While attempts have been made to suggest policy options for addressing emerging zoonoses (Coker et al. 2011), the 
status quo has prevailed, with individuals continuing to eat meat in growing quantities and governments failing to minimize the threat of zoonotic pandemics.

Importantly, the intensification of animal agriculture is not simply a problem for highincome countries, but is a global conundrum. Among others, China and Brazil have seen rapid growth in land-use change such as deforestation due to need for cropland and pastureland and the expansion of CAFO-based farming. The problem of zoonotic disease risk is global and, in the absence of a global governing body, solutions must include the intervention of federal governments.

\section{The Public Health Ethics Case for Reducing or Eliminating Intensive Animal Agriculture}

The public health effects of zoonotic outbreaks like COVID-19 include - but are not limited to - deaths (just under 3 million globally as of this writing), infections (138 million globally as of this writing), complications and chronic or permanent effects of infection on individuals, strains on hospitals and the health care system, often outsized impacts on at-risk and marginalized communities (Wadhera et al. 2020; Stewart 2020; Lopez et al. 2020), and broad economic impacts ranging from job loss to disrupted international trade (Parker et al. 2020), which in turn can have carry-on public health impacts (Braveman et al. 2010). In the United States, the total cost of the Covid-19 pandemic has been estimated at \$16 trillion (Cutler and Summers 2020).

Given the breadth of these impacts and the fact that other zoonotic pandemics are highly likely - a matter of when and not if - the key public health ethics question that emerges is about whether it is ethically appropriate for governments to intervene into food production and consumption in the interest of collective public health. These considerations are not entirely novel. After the SARS outbreak, the American Public Health Association called for a moratorium on new intensive animal production facilities (Akhtar et al. 2009). And amidst the ongoing Covid-19 pandemic, some economists have called for policies aimed at curbing meat consumption and "aligning the incentives of food producers with the common good" (Espinosa et al. 2020). Given that such policies involve interfering with the plans of individuals and entire industries, however, a natural question concerns whether governments are morally permitted to implement them.

This article considers three distinct measures that could be employed to reduce or eliminate the risk of zoonoses, which draw on the Nuffield Council on Bioethics 'ladder' of interventions. The ladder is a taxonomy of public health interventions organized by the extent to which the measures (purportedly) infringe upon individual liberty (Nuffield Council on Bioethics 2007).

The three options we propose fall into the four upper rungs of the ladder which represent the most intrusive policy options: incentivizing choice, disincentivizing choice, and restricting/ eliminating choice. The Nuffield Council Ladder identifies these different measures, in part, because they call for justification, given that they involve significant government interference with the liberty of individuals.

We focus on potential supply-side government interventions into the production of foods through intensive animal agriculture specifically because the measures we suggest - including taxation, subsidies, and the banning of specific forms of production - fall exclusively within the purview of the powers of federal governments. We do not address demand-side 
interventions that seek to shift consumer behavior - and which others have suggested to reduce meat consumption - such as educational programs (Willet et al. 2019) or public-facing informational campaigns and behavioral nudges (Godfray et al. 2018, Hansen et al. 2019, Bonnet et al. 2020), but our analysis could inform an analysis of the ethical permissibility of such efforts. We adopt the relevant focus in part because, as noted earlier, we doubt these sorts of demand-side programs would suffice to address the relevant public health risks. Furthermore, we provisionally accept the assumption behind the ladder-that interventions on 'higher' rungs stand in greater need of justification than those on lower rungs. Put succinctly, banning intensive animal agriculture faces a higher justificatory burden than providing citizens with information about the connection between intensive animal agriculture and zoonotic disease. If we can show that these more intrusive measures are justifiable, then presumably a host of less intrusive measures on the ladder, are also justifiable. (The lower rungs, which we do not consider, include altering choice architecture, commonly referred to as 'nudging'; enabling choice by, for example, paying for optional smoking cessation classes or ensuring access to clean water; and providing information to consumers, such as in food labels or public service announcements.)

The three options from the Nuffield Ladder that we consider are as follows:

The first, and arguably least intrusive public health intervention, involves incentivizing alternative choices. Subsidies and tax credits for solar panels and electric vehicles to reduce greenhouse gas emissions and their associated harms are an example of this sort of measure. One clear alternative to intensive animal farming that might be readily accepted by the public are plant-based, fermentation-based, and cell-based meat, dairy, and egg alternatives (alternative proteins) whose production does not generate the same zoonotic risks. Plant-based ASF alternatives are a fast-growing market segment and it is likely that these alternatives will continue to gain in popularity, potentially filling the "role" of animal source foods for consumers. And while not yet available for mass consumption, cellular meat - animal tissue grown from stems cells in a bioreactor - also promises to reduce switching costs for consumers away from conventional meat (see Stephens et al. 2019 for an overview of this technology). Indeed, some have claimed that developing such alternatives precisely for this reason is ethically justified (Hopkins and Dacey 2008). To differing degrees, alternatives offer some potential environmental and health benefits over conventional animal source foods (Santo et al. 2020), but across the board they require fewer plant and animal inputs than animal sourced foods, so they have a far lower zoonotic risk profile. To mitigate zoonotic risk associated with intensive animal agriculture, governments could incentivize research and development and/or large-scale commercialization of high-quality and low-cost alternative proteins to facilitate a consumer shift.

Second, public health disincentivizes the relevant behavior that poses a public health risk by attaching costs to it. In the case of consumer goods harmful to public health, governments impose either sales taxes or Pigouvian taxes on products deemed to cause a threat to public health such as soda (Pomeranz 2012) or cigarettes (Viscusi 1995) to disincentivize either production or consumption or both. Sales taxes are aimed at disincentivizing individual consumption by forcing disaggregated individuals to decide whether they are willing to pay a surcharge on a given product. However, given that animal source food production can lead to the outbreak of zoonotic disease that can harm both consumers and non-consumers, the goal of disincentivizing both production and consumption is better achieved by a Pigouvian tax - a "zoonotic tax" (Espinosa et al. 2020 1037) - on meat. This proposal is based on extant proposals that Pigouvian taxes should be applied to meat production to factor in the costs it 
imposes on public health in the form of noncommunicable disease (Springmann et al. 2018), environmental harms such as greenhouse gas emissions (Godfray et al. 2018; Säll and Gren 2015), or both (Katare et al. 2020). The reasoning here is that governments are permitted to impose such a tax in cases where the price of a given good does not reflect its true costs of production and their externalities, and that such a regulatory failure is best addressed by forcing producers to internalize the costs of the harms their products may cause (Pigou 2013). The public health analog here is the use of carbon taxes to disincentivize the production or use of carbon to achieve beneficial environmental and public health outcomes such as reduced risk of stroke, asthma exacerbation, or premature mortality among populations affected by air pollution (Ambasta and Buonocore 2018; see also Espinosa et al. 2020). Such a tax forces producers to factor in increased prices into their production and pricing decisions and, theoretically, decrease production or pass on higher costs onto consumers, thereby theoretically decreasing consumption. To take another example, the Comprehensive Environmental Response, Compensation, and Liability Act of 1980 attempts to ensure that potential polluters pay for cleanup and compensation for hazardous waste (H.R. 7020 1980). While the pragmatics of this proposal in the context of ASF and zoonotic disease would be tricky given that different outbreaks will have different costs, which cannot be estimated ex ante, the costs of Covid-19 could serve as a benchmark for an industry-wide tax meant to both disincentivize overproduction and even fund a response fund for future zoonotic pandemics.

The third and arguably most intrusive kind of intervention from the ladder that we consider involves the government restricting or eliminating choices. Requiring motorcyclists to wear helmets, compulsory vaccination (making it illegal to go unvaccinated) and enforced quarantines would fall under these two categories. Eliminating choice can also entail banning the production of goods such as lead-based paint or asbestos whose use poses a public health risk. In the context of mitigating the risk of zoonotic pandemics, if we treat intensive animal farming as a public health risk, governments might consider making the practice illegal. Of course, given the disruption to food supply chains and both local and national economies, such a ban would have to be carefully enacted. It is beyond the scope of this article to lay out a complete roadmap for such a policy, but it would require making all animal farming over a certain small size limit illegal (including an immediate ban on new operations and a phase-out schedule for existing ones) and, ideally, involve a just transition scheme to make the shift away from current agricultural production less burdensome on producers and consumers. The aim of a ban, however it would be enacted, would be to (eventually) eliminate all intensive animal production systems.

Having canvassed these three different kinds of public health measures, it's worth turning to different justifications for public health interventions, and considering the extent to which they count in favor of the relevant measures.

\section{Overall Benefit}

Perhaps the most straightforward rationale for any public health intervention involves the claim that the intervention will produce an overall benefit (Faden et al. 2019, 2020). Being at less risk from zoonotic diseases certainly seems to yield a net benefit for the population. The benefits in question are both direct and indirect (Espinosa et al. 2020, 1027-1028). By 'direct benefits,' we mean reducing overall incidence of illness and death. Taking the COVID-19 pandemic as an example, globally there have been over 138 million cases and 3 million deaths 
as of April 15th, 2021 (World Health Organization 2021). To the extent that the relevant measures preclude future pandemics, they will yield this benefit.

Pandemics also impose indirect costs. Think, for instance, of other preventive measures that governments take, such as shutting down various businesses and schools. While estimates vary, some suggest that containment measures have led to a loss of two percentage points of overall GDP per month that these measures are in place (Organisation for Economic Cooperation and Development (OECD) 2020). We should expect future pandemics to also impose significant indirect costs. While such costs cannot be estimated precisely and therefore it is difficult to say with certainty whether the costs imposed by the measures we suggest (and especially a complete ban on intensive animal agriculture) would outweigh the costs of any future pandemic, the precautionary principle suggests that "if the risk is difficult to manage and anticipate, and can hardly be shared once it occurs, the role of early self-protection becomes further emphasized; specifically, reducing the probability of a pandemic at the source." (Espinosa et al. 2020 p.1037).

So, if one accepts that governments are permitted to try to benefit the populace as a whole by improving public health, then there's a prima facie justification for governments to enact policy that infringes on the liberty of producers in order to reduce the risk of future zoonotic pandemics. Appealing to overall benefit, then, would seem to support an especially broad variety of policy measures aimed at eliminating this risk. Subsidizing the production and commercialization of foods that involve less risk of zoonotic disease and taxing producers would both appear to yield an overall benefit by creating incentives not to impose risk and disincentives to impose risk, respectively. But there is no special reason to stop at these measures. Indeed, overall benefit seems to provide a prima facie case for a permission on the part of governments to institute an outright ban on intensive animal agriculture.

The claim that overall benefit suffices to justify each of the policy measures involves an empirical claim and a normative one. The empirical claim is that the relevant measures will, in fact, yield a net benefit. The normative claim is that this net benefit suffices to justify the relevant measures. Critics will dispute both claims. We will return to the empirical dispute below. The objection to the normative claim motivates alternative justifications for the relevant policies. For instance, many have charged that core commitments of liberalism prohibit such actions - the power of government should not be invoked to maximize overall benefits, but must instead be restricted to solving collective action problems, preventing harm, or realizing principles of justice - principles of justice that do not countenance maximizing overall benefits (e.g., Anomaly 2011; Quong 2011; Gaus 2011). In what follows, then, we suggest that these other rationales would also license the proposed policies.

\section{Solving Collective Action Problems and Preventing (Collective) Harm}

As noted, one distinct rationale for various policies under discussion focuses less on overall benefit and more on the role of government in solving collective action problems. A widely endorsed claim is that governments have a legitimate role in solving collective action problems pertaining to population health (Anomaly 2011; Dees 2018; Horne 2019; Bernstein and Randall 2020). Ensuring access to clean air, clean water, or making sure that a population enjoys herd immunity all involve the government solving health-related collective action problems. For instance, individuals may wish to free ride on the choice of other parents to vaccinate their children and enjoy herd immunity, but if too many parents do so, then the public good of herd immunity is lost. Given that private actors lack the incentive to solve this 
problem, many argue that government may implement a policy to avoid the loss of the relevant public good - policy such as mandates that forbid children from attending public school if they do not receive certain vaccines (Anomaly 2011; Brennan 2018; Giubilini 2019a; Giubilini 2019b). Notably, even various proponents of small government, such as self-described libertarians or classical liberals, treat solving collective action problems as morally appropriate grounds for public health intervention (Anomaly 2011; Brennan 2018).

Intensive animal agriculture generates two health-related collective action problems that governments would seem to be well-suited to solve - and therefore government intervention could be justifiable on these grounds. First, intensive animal agriculture incentivizes the creation of novel human-animal interfaces that, in turn, cause zoonotic diseases that impose health risks on all of us. Markets on their own will not disincentivize such practices; indeed, growing global demand for meat incentivizes participation in animal source food markets and associated land-use change for animal feed crops and intensification of animal farming. If we accept that governments may solve collective action problems that negatively affect population health, then that rationale would extend to disincentivizing participation in animal source food markets, or even, perhaps, preventing those markets from existing at all.

A second collective action problem is a free-rider problem that concerns who bears the costs of outbreaks that originate in CAFOs or through land-use change to support animal agriculture. Put bluntly, producers of intensive animal agriculture do not have much, if any, incentive to voluntarily pay taxes to offset the costs they impose on everyone else. Since solving health-related collective action problems like this often gets cited as a good reason for public health intervention generally, this case should be no different; governments should step in to ensure that producers pay for the costs they impose on third parties.

On this view, there is a strong case to be made that a zoonotic tax may be implemented to address the collective action problem of zoonotic risk by disincentivizing the production (and consumption if cost is passed on to consumers by producers in the form of higher prices) of products that generate harmful externalities.

Importantly, one could grant that government has a role in correcting for a market failure like this one and ensuring that producers compensate those harmed by pandemics but deny that this licenses anything more than a zoonotic tax. Instead, producers in intensive animal agriculture may continue their production practices, so long as they compensate individuals negatively affected by zoonotic diseases - especially individuals who do not consume the relevant products. An appeal to solving collective action problems would seem to justify, at the very least, these sorts of measures, but one could argue that this is all that the appeal to solving collective action problems would justify.

This line of reasoning, however, encounters a few problems. One natural worry is that these measures will not, in fact, solve the first collective action problem we mention - namely, that the current system of food production incentivizes many practices that lead to increased risk of zoonotic diseases. Taxation, on its own, may not disincentivize enough production to reduce the drivers of zoonotic disease enough to seriously reduce the risk of future outbreaks and therefore to solve this collective action problem.

Recall the second collective action problem arises because producers impose significant costs on the rest of us by contributing significantly to the risk of a pandemic, but have no incentive to pay for those costs. Yet, as we have argued, the economic damage caused by pandemics is enormous. So, if we are concerned with preventing free riding, then producers would need to pay for the costs they impose on others in the form of pandemics. Even if we grant that intensive animal agriculture is not solely responsible for pandemics - and so 
producers do not need to pay this full amount - it is unlikely that major producers could compensate as much as they owe.

So, even if we restrict our focus to solving the collective action problems related to zoonotic diseases that arise due to current agricultural practices, it would appear that measures in addition to taxation are justifiable. In particular, subsidizing alternative food production methods would generate incentives for producers to choose to engage in other forms of production. In other words, one way to solve a collective action problem involves introducing disincentives, and another way involves introducing new incentives. If we accept that solving a collective action problem justifies public health intervention, then there's an initial strong case for both taxes and subsidies for alternatives.

Finally, restricting choice by banning intensive animal agriculture could solve the relevant collective action problem too and therefore is, at least prima facie, justifiable as a policy option-although we consider objections to this claim below.

\section{Preventing Harm or Rights Violations}

We just considered the claim that producers impose costs on others, and noted how these producers lack an incentive to compensate those who bear these costs. A nearby but distinct justification for policy claims that, by imposing risk in the form of zoonotic disease, producers harm others, or violate their rights. Importantly, this view rejects the premise that imposing costs associated with zoonotic diseases is permissible on the condition that compensation is provided. This is because if individuals have rights against being exposed to some amount of risk of harm, it is not as though others are permitted to impose that degree of risk and then compensate the individual if the risk eventuates (Mack 2015; Flanigan 2014a; Brennan 2018). Instead, rights constrain what sorts of risks individuals may permissibly impose on others to begin with. For example, individuals do not have a right to fire a rifle in the air and then compensate bystanders who are unlucky enough to be struck by the gunfire (Flanigan 2014a, 6-8); and individuals are not permitted to expose non-consenting adults to second-hand smoke so long as the exposed partiesreceive compensation.

So, the question is whether a similar rationale can be proffered to justify policies that mitigate or prevent the imposition of zoonotic risk. One natural way to think about the ethical significance of these other-regarding risks involves what has come to be called 'the harm principle'. This principle articulates a constraint on intervening with the liberty of otherseither through the pressure of powerful public opinion or through coercively enforceable law (Mill 1869). Such interventions are morally permissible only if the interfered-with-action harms others or imposes significant risk of harm to a non-consenting adult. Harms involve setting back someone else's interests, and while there are live debates about the difference between a harm and a mere cost, presumably exposing others to risk of infectious disease counts as a harm (Brennan 2018; Flanigan 2014a). Indeed, many arguments about the ethics of infectious disease accord the harm principle pride of place when it comes to justifying government intervention (Giubilini 2019a; Giubilini 2019b; Navin 2016; Holland 2007; Faden et al. 2020).

The parallel we wish to draw is probably evident. Intensive animal agriculture imposes risks of harm in virtue of its role in causing - or contributing to causing - outbreaks of zoonotic diseases. Now, Mill's harm principle does not claim that mere harm-imposition suffices to justify liberty-restricting regulations. Rather, he claims that when an action imposes harm on another non-consenting adult, regulations should be assessed with an eye to how they affect 
overall utility (Mill 1869). Yet $\S 2.1$ makes a prima facie case that each of the policy measures we have discussed would, in fact, promote overall utility. So, the harm principle appears to justify restricting the behavior of intensive animal agriculture producers - to prevent them from harming third parties by exposing those third parties to risk of infectious disease. So, it would seem, the harm principle would provide some justification for each of the policy measures-including elimination.

Three complications arise for this appeal to the harm principle. The first concerns whether we could eliminate this risk without significantly reducing overall production or radically altering the status quo, for instance by increasing biosecurity on farms (as noted by Espinosa et al. 2020). Yet we have already seen that current production incentivizes other practices that generate harms, and even comprehensive biosecurity measures are not necessarily reliable (Dutkiewicz 2020; Espinosa et al. 2020). That is, animal agriculture in its current form, even if made safer or more biosecure, would neither completely prevent zoonotic risk nor disincentivize land-use change, the wild animal trade, the continued operation of spaces like wet markets which cannot be made safe in the relevant ways. As long as animal agriculture exists on its current scale, we should worry that we will be at significant risk from viruses like swine flu, avian flu, or SARS-CoV-2.

A second complication arises because the harms in question involve the level of risk involved. The harm principle does not permit government intervention to prevent the imposition of any risk of harm. The risk must be substantial, in some sense. Jason Brennan makes this point when considering whether the risks involved in going unvaccinated constitutes a rights violation, citing Robert Nozick: 'Imposing how slight a probability of a harm that violates someone's rights also violates rights?' (Nozick 1974, 74). In other words, the decisions of producers do impose a risk of harm on the rest of us by engaging in the practice of intensive animal agriculture. Yet we might worry that the risk does not rise to the level of a rights violation for the harm principle to apply.

A third, and related complication for appealing to the harm principle arises because the harms from intensive animal agriculture involve collective harms. While a particular zoonotic disease might originate from a particular CAFO, it's not as though any single factory farm exists in a vacuum. Rather, a system of production yields the relevant results - it's the decisions of producers, taken collectively, to breed and kill animals that really risks the emergence of new zoonotic diseases. In other words, it is the system of factory farming that presents the relevant risks and we can never know in advance at which farm the next pandemic will originate. To return to the analogy of smoking, the harms of second-hand smoke are direct, as they can be traced directly to the production of cigarettes and the smoker's action of smoking. Most individual meat producers and individuals' consumption of meat, by contrast, do not directly cause the emergence of zoonotic diseases or directly ensure that individuals will be at higher risk of contracting a communicable disease. Given the indirectness of the harm, then, one might argue that appealing to the harm principle fails to justify measures that go beyond taxation.

While these features of intensive animal agriculture complicate arguments from the harm principle, there are other nearby principles that attempt to accommodate similar worries in other public health ethics debates. For instance, Brennan invokes his 'clean hands principle' to justify vaccine mandates (Brennan 2018). He argues that individuals have a coercively enforceable moral obligation to refrain from participating in activities that, taken collectively, impose unacceptable risk of harm. On these grounds, he argues that parents have a coercively enforceable obligation to vaccinate their children against measles mumps and rubella, and 
perhaps other diseases too. Brennan's point is that the individual who goes unvaccinated does not, in a vacuum, impose unacceptable levels of risk; the real risk concerns the loss of the public good of herd immunity. Brennan argues that vaccine mandates are justified in virtue of preventing individuals from contributing to unacceptable risk of harm in the collective case. If we accept this line of argument in the context of vaccine-refusal, then it seems natural to apply it to the case of animal agriculture. Just as one individual's decision to go unvaccinated does not guarantee that the public good of herd immunity is undermined nor that someone else will contract the disease, the decision to operate a single CAFO does not guarantee the outbreak of zoonotic diseases that will, in turn, infect a particular person. Nonetheless, it does involve participating in an activity that, collectively, imposes risk of outbreaks of zoonotic diseases.

As noted, Brennan's application of the clean hands principle applies to unacceptable risk of harm, rather than just any risk of harm. So, this argument needs to show that the relevant risks are unacceptable. Here Brennan follows Sven Hansson, who argues that risks are acceptable "if and only if this exposure to risk is part of an equitable social system of risk-taking that work to her advantage" (Hansson 2018). As we have already argued, however, the exposure to risk in the form of zoonotic disease does not work to the advantage of each. Indeed, as we will argue below, there are real reasons to think that the current food production system constitutes an inequitable social system of risk-taking that does not work to the advantage of many vulnerable members of our society. Accordingly, it would seem that the same line of argument that justifies government intervention aimed at mitigating other cases of collective riskimposition applies to intensive animal agriculture in its current form.

A second application of the harm principle to indirect harms comes from Jonny Anomaly, who argues for regulating factory farming on public health grounds - albeit with a focus on how current production practices involve excessive use of antibiotics, and thereby increase the risk of emergence of antibiotic-resistant bacteria. In this context, Anomaly appeals to Gerald Gaus' 'Public Harm Principle,' which states, 'If (1) an accumulation of X-ing sets back other people's welfare interests, and if (2) the harm is serious enough such that its prevention warrants limiting the liberty to X (either by regulating or prohibiting X-ing), then (3) everyone should carry their fair share of the burden... and (4) everyone who Xs is responsible for a share of the harm done." (Anomaly 2009, 431; Gaus 1999, 197).

If one accepts Anomaly's application of Gaus's Public Harm Principle in the context of factory farming contributing to the emergence of antibiotic-resistant bacteria, then one should accept that it applies to zoonotic disease as well. That is, (1) the accumulation of intensive animal agriculture sets back people's welfare interests by exposing them to significant risk of zoonotic disease, or the costs that accompany a pandemic. And (2) the relevant harms are quite severe. While we will consider (3) and (4) in more depth below, it seems fair that producers should have to shoulder significant burdens for the harms they impose on others.

Where does this leave arguments that appeal to prevent harm or rights violations? While none of the three options we suggest are necessarily mandatory, the arguments in this section constitute a prima facie case for each.

\section{Other Considerations of Justice}

The final form of justification that we invoke to make the public health case for the permissibility of radically altering agricultural practices appeals to the value of justice. The basic idea is that just as principles of justice should regulate how economic, political and legal institutions distribute valuable goods, principles of justice should also be sensitive to how 
various institutional arrangements impact public health. We focus here on theories of justice which claim that government's public health mandate has its source in the role of government in realizing principles of distributive justice (Powers and Faden 2006; Powers 2019; Daniels 2008; Nussbaum 2006, 2011; Ruger 2010).

The pandemic and the different governments' responses have had profound effects on the distribution of a variety of valuable goods - including wealth and income, health, opportunities for work, and education, to name just a few prominent ones. Theories of distributive or social justice typically treat these sorts of goods as governed by principles of justice (Rawls 1999; Sen 1999, 2009; Nussbaum 2006, 2011; Daniels 2008; Powers and Faden 2006; Powers and Faden 2019; Ruger 2010). That is, theories of justice typically focus on some subset of goods that are important to most or all people, regardless of their particular aims, and they focus on how different social arrangements lead to different distributions of these goods. Any such theories include distribution-sensitive principles according to which one's income, gender, race or ethnicity, or particular conception of the good should not determine one's share of these goods.

In the case of the United States, for instance, while New York Governor Andrew Cuomo infamously proclaimed that COVID-19 is the great equalizer, affecting all of us equally, (https://twitter.com/NYGovCuomo/status/1245021319646904320) we now know that this is not the case. The burdens of the COVID-19 pandemic have, predictably, differed for individuals - falling especially hard on those from already disadvantaged socioeconomic, racial, and ethnic groups (Van Dorn et al. 2020). To begin with the most direct sorts of costs, disease burden has fallen disproportionately on people from low-income backgrounds and people of color-Black and Latinx individuals, as well as Native Peoples. Various scholars have argued that the cause for this disparity is partly due to pre-pandemic social conditions (Wadhera et al. 2020; Stewart 2020; Lopez et al. 2020). Individuals from these groups disproportionately receive inadequate medical care, they live in environments with high levels of various kinds of pollution and food insecurity, and thus they are already at elevated risk of diabetes, hypertension, heart disease, or asthma - conditions that put one at higher risk of death from COVID-19.

Individuals from these groups have not only made up a disproportionate number of cases and deaths; they have disproportionately borne other important burdens during this time, such as loss of employment or significant financial difficulties (Parker et al. 2020). Children from lower-income backgrounds are less able to engage in distance learning than their wealthier peers - sometimes due to lack of access to the requisite technology or because their parents lack the time or education to help supplement remote instruction (Faden 2020; The New York Times 2020). And lack of access to educational and economic opportunities, in turn, are correlated with worse health outcomes (Braveman et al. 2010). In other words, on many theories of justice designed to assess public health interventions, this pandemic has exacerbated salient pre-pandemic injustices.

For many readers, these points will be familiar and uncontroversial, or even obvious. Nonetheless, they take on a new moral significance once we recognize the role of intensive animal agriculture in causing outbreaks of zoonotic disease. While the exact causes of the current pandemic are still being determined, we know that intensive animal agriculture has played a significant causal role in other outbreaks and pandemics. And given how intensive animal agriculture plays a major role in driving the emergence and spread of zoonotic disease, we should recognize that it is a source of injustice. When institutional arrangements lead to unfair distributions of the sorts of goods we have discussed, then theories of justice like the 
ones we have mentioned call for radically reforming those institutions. Our claim is that this pandemic should help us to realize that animal agriculture constitutes an institution, or set of institutions, that plays a major role in exacerbating injustice. Accordingly, it would at the very least be permissible, if not obligatory, from the perspective of justice to implement the policies we have proposed.

\section{Objections}

Having made the initial case for incentivizing alternatives to, disincentivizing the production of, or even eliminating intensive animal agriculture it's now worth considering some salient objections to the lines of argument we have put forward, as well as some concerns that naturally arise for arguments in defense of public health interventions like the ones we propose, more generally. While hardly exhaustive, the objections we consider are especially salient and pressing - and, so, our response to them only further bolsters our positive argument.

\section{Overall Benefits?}

A first natural objection focuses on the argument that appeals to overall benefit. This objection grants that the risks of zoonotic diseases are real, but insists they are worth it due to the economic, nutritional, and other benefits associated with intensive animal agriculture. Whether this claim is correct turns on the alternatives to intensive animal agriculture. For instance, if the choice were between malnutrition and outbreaks of zoonotic diseases, then there would be a difficult choice here. However, diets that optimize human and planetary health, such as the EAT Lancet diet (Willet el al 2019), recommend major reductions in meat consumption, especially in high-income countries. While some low-income countries fall short of the recommended nutritional standards of such a diet, including in terms of animal source foods, others far overshoot it, including specifically those high-income and rapidly-growing countries (like the United States, Brazil, and China, among others) to whom our argument applies. Adhering to an EAT Lancet diet given existing food production and distribution systems is already financially within the reach of most consumers in high-income countries (although in lower-income countries this is not necessarily the case) (Hirvonen et al. 2020).

Moreover, as briefly suggested above, current dietary patterns have their own health costs, even if we put aside concerns about zoonotic diseases. Red meat consumption alone has been linked to approximately 860,000 deaths globally per year and total health care costs of $\$ 285$ billion (Springmann et al. 2018). In other words, it is not as though intensive animal agriculture results in a bad public health outcome from the perspective of zoonotic disease but a good health outcome from the perspective of current dietary patterns. So, the claim that intensive animal agriculture yields a net benefit for overall population health seems implausible; other food production systems, or even simply the reduction or elimination of animal production in our current system, would surely be better.

One final consideration here is whether the economic benefits of intensive animal agriculture outweigh the economic costs of restricting, replacing, or banning it. Globally, the meat industry produces over 335 million tons of meat (FAO 2019) and records - depending on methodological approach and scope - between $\$ 1$ and 2 trillion in annual revenue and employs millions of laborers. One might object that restricting this economic activity is harmful both to 
national economies and to laborers - and so the policies we have recommended do not, in fact, yield a net benefit. Two points work against this claim, however. First, some estimates suggest that the total financial benefit in environmental and health savings of a move away from a meat-centric diet toward a predominantly or entirely plant-based one could result in between $\$ 1$ and 30 trillion dollars of economic benefits (assuming a transition through the year 2050) (Springmann et al. 2018). Second, as the Covid-19 pandemic has shown, numerous industries other than meat are severely harmed by pandemics, as are the laborers employed by those industries. Moreover, meat industry laborers, and specifically slaughterhouse workers, have been disproportionately harmed by the Covid-19 outbreak (Middleton et al. 2020). It is hardly in the interest of overall benefit from the point of view of economic, public, or environmental health to protect one industry when the potential harms caused by that industry (due to its contribution to potential zoonotic pandemics), including to its own labor force, outweigh its benefits and put other industries and laborers at risk.

\section{An Unfair Distribution of Benefits and Burdens}

Even if we grant that eliminating intensive animal agriculture might yield a net benefit, a natural rejoinder would be that it is still unfairly burdensome on producers, laborers, and at least some consumers. The ASF industry generates considerable economic benefits and employment globally. Some individual producers or farmers in this value chain may also have a sense of fulfillment, or even identity, tied up with this practice. So, it might seem that taking steps to significantly reduce or eliminate intensive animal agriculture unfairly burdens individual producers in the animal sourced food supply chain and their workers. Yet here there are a few replies.

As we have suggested, there are real costs for many who work in these industries. In particular, we have seen that workers in intensive animal agriculture are especially at risk of zoonotic disease, not to mention a slew of other occupational safety risks including injury and other forms of illness (Fitzgerald 2010). These risks do not suffice to justify, on paternalistic grounds, taking away this kind of work. Working in conditions where one is paid minimum wage and at heightened risk of zoonotic disease may be preferable to unemployment for many individuals. Nonetheless, if the objection rests on the value of working in industrialized animal agriculture, we should not overstate that value — and, accordingly, we should not overstate the loss of value if the industry is significantly reduced or eliminated.

Second, and relatedly, absent considering alternative food production systems, we cannot fully assess the extent of loss or gains that changes in production will yield. Perhaps jobs that are more fulfilling or put employees at less risk will become available. Proponents of economic policies like the Green New Deal commit to finding better work available for those who will lose out from collectively weaning ourselves off of environmentally harmful activities via job guarantee or just transition programs. Early assessments of such proposals have found that, while not seamless, they are feasible (Galvin and Healy 2020). The extent to which we can mitigate the costs borne by those who lose their job will inform assessments of the justness of reducing or eliminating animal agriculture. Since we are not proposing particular alternative systems in this paper, it is also beyond the scope of the paper to fully assess whether the alternatives will make up for the losses people experience. However, it bears noting that a mass-scale transition to alternative protein production would likely involve many jobs in warehousing, processing, and logistics that already currently exist within the intensive ASF production value chain, meaning that many jobs could theoretically be saved if investment in 
alternative proteins is pursued. Moreover, alternative proteins could well offer business opportunities to incumbent companies already in the conventional ASF business. In any case, we should not assume that eliminating intensive animal agriculture will necessarily be a net loss for those who currently work in that industry. Moreover, an argument that appeals to these sorts of losses only implies that if we do in fact reduce or eliminate intensive animal agriculture, we should consider ensuring that those who lose their jobs should be compensated appropriately — not that reducing or eliminating animal agriculture is prohibited because of the losses it might entail for some.

A third, less conciliatory reply is as follows: as we have seen from the discussion of imposing costs or harms, the business model of intensive animal agriculture producers is imposing significant costs and harms on others-including illness itself as well as associated economic costs. In other cases where individuals impose costs or harms on others through their livelihood - such as in the case of environmentally destructive industries like coal mining - we do not typically judge that the interest in keeping one's livelihood or a fulfilling line of work (be it for individuals or companies) justifies imposing those costs. In other words, one can grant that reducing or eliminating animal agriculture has genuine costs for producers and labor without also accepting that such costs are unfair or unjustifiable. Accordingly, it is not at all apparent that these industries are entitled to continue a line of work that imposes costs on the rest of us.

Finally, in the United States and many other countries, unemployment has soared in the wake of the pandemic. Once we recognize the causal role of intensive animal agriculture in pandemics, then we can recognize that animal producers are contributing to other people losing their jobs due to the economic and policy effects of pandemics. If one's own work plays this role in causing not only illness and economic loss but also unemployment, appeals to entitlements to continue in one's current line of work seem far less compelling.

What about consumers? Significantly reducing or eliminating intensive animal agriculture will mean that various foods will be less available. Here one might appeal to intensivelyproduced animal sourced foods' cost-effectiveness, wide availability, gustatory value, or cultural or other significance for people. Even if one is convinced by the replies to concerns about producers, one might insist that consumers, or some subgroups of consumers, will be made worse off by policies that significantly reduce or eliminate intensive animal agriculture.

Our first reply builds on an earlier point. Namely, we cannot fully assess how well-off consumers will be without considering particular alternatives, and it is beyond the scope of this paper to consider these alternatives in depth. Nonetheless, a variety of alternatives to conventional animal source foods are already available such as plant-based meat, milk, and egg alternatives that would do well along at least some of the dimensions of value we have mentioned - cost-effectiveness, gustatory value, and perhaps even cultural significance - and that animal sourced foods produced using smaller-scale, alternative methods would at the very least satisfy gustatory and cultural demands, albeit at a higher price. Indeed, our suggestion that governments invest in alternative protein research and commercialization would go a long way toward satisfying consumer demand within the current food system but without intensive animal agriculture and its incumbent public health risks.

Our second reply will also be familiar. Namely, just as the entitlements of producers in one industry do not extend to imposing devastating costs on the rest of us, consumers of the product of that industry are not entitled to that product despite its devastating costs for the rest of us. For instance, just because a smoker gains gustatory pleasure from consuming cigarettes does not suffice to show that smokers may expose others to the health risks associated with 
second-hand smoke, nor does it necessarily suffice to undermine the case for policies that aim to reduce these risks.

\section{Causes of Injustice and Animal Agriculture}

A line of objection to our justice-based arguments notes that even though intensive animal agriculture plays a significant role in outbreaks of zoonotic diseases, it does not cause the prepandemic injustices that are exacerbated by these outbreaks. It would be inappropriate to hold producers responsible for injustices that do not solely concern the global food production system. Accordingly, considerations of justice should lead us to focus less on intensive animal agriculture and more on (a) the unjust circumstances that lead zoonotic diseases to exacerbate the effects of pandemics, or on (b) policy measures in response to pandemics that affect these considerations of justice.

This objection, however, rests on a false choice. Rather than thinking that governments should choose between addressing underlying injustices or addressing how intensive animal agriculture exacerbates those injustices, there are good reasons to do both. If efforts at addressing injustices fail or take longer than expected, potential outbreaks of zoonotic diseases will continue to exacerbate them nonetheless - and, so, government should step in to address the causes of potential outbreaks. To illustrate with an analogy: some people live closer to polluting factories than others, suffering ill health effects as a result, and they live closer to these factories because of injustices. Perhaps individuals live near such factories because of discrimination in real estate markets, government policies like redlining, or political-economic systems or institutions that lead to gross income inequality that confines people to those conditions. Living close to these factories, in turn, exacerbates health inequalities due to exposure to pollution. On the views of justice we're endorsing, governments should certainly attempt to address the underlying injustices that lead people to live near the factories and suffer the resultant ill health effects. But there are also reasons to try to prevent factories from exacerbating these injustices, for instance by restricting their capacity to pollute or shutting them down. The fact of existing background injustice does not permit these factories to engage in activities that exacerbate health inequities or other injustices.

Returning to our main focus, even though pandemics exacerbate pre-pandemic injustices, this does not mean that practices that may cause pandemics should be viewed as morally innocent from the perspective of justice. Rather, steps should be taken to both reduce the background injustices and to reduce the risks imposed by the relevant practices. This argument becomes more powerful still if one thinks it is unlikely that we will ever live in a perfectly just society in which pandemics do not disproportionately burden the least well-off. If that is correct, then government should strive to mitigate the injustices suffered by the least welloff — both by addressing background injustices and by addressing factors that exacerbate those injustices. One might argue that governments should actively subsidize lost wages and small business losses, take aggressive steps to ensure that low-paying jobs and at-risk populations have free access to personal protective equipment and health care, and perhaps even enjoy some degree of priority when it comes to access to drugs or vaccines (if these exist for a given disease). But even accepting all of this hardly supports the claim that animal source food producers should be free to impose the relevant risks in the first place, given that these may necessitate such policies and incur attendant costs. Moreover, here again we should worry that policy measures in response to a pandemic will not be as responsive to injustice as they need to be; it would be unrealistic to think that government could develop disease control policy or 
other measures that perfectly respond to the relevant injustices in the midst of a pandemic, and so it should take steps to prevent the relevant injustice-exacerbating event from occurring in the first place.

\section{Paternalism}

A distinct line of objection to our argument is familiar from debates about public health policy. Justifications of government policy that appeal to promoting population health often face challenges from anti-paternalists. While defined in many ways, for our purposes, paternalism involves, "the interference of a state or an individual with another person, against their will, and defended or motivated by a claim that the person interfered with will be better off or protected from harm" (Dworkin 2020). Even if eliminating intensive animal agriculture would yield a net health benefit or protect the individuals that comprise the population from harm, producing that benefit would go against the will of many people - simply to protect them from themselves; such an intervention would be paternalistic.

To illustrate with an analogy: even if they yield an overall benefit to population health, motorcycle helmet mandates, soda taxes, and bans on trans fats or even cigarettes ultimately produce this benefit at least partly by protecting consumers from themselves. Yet at least some consumers do not wish to be protected (Jones and Bayer 2007, 213). In such cases, those who accept the normative premise that paternalism is unjustifiable will also accept that such policies - helmet mandates, trans fat or cigarette bans, and soda taxes - are unjustifiable.

Returning to intensive animal agriculture, then, we might think that bans on the production or sale of foods derived from intensive animal agriculture, or perhaps a significant tax designed to reduce overall production, or even the promotion of alternative products, count as instances of paternalism. Even though these measures might protect the overall population, they do so by protecting the consumer from herself. Yet the consumer freely chooses to purchase animal products, so one might claim she effectively accepts the risks that accompany intensive animal agriculture. Moreover, the appeal to the harm principle or something like it includes the qualification that the harm in question must be non-consensual. Perhaps one could argue that consumers do consent to the relevant risk, given their decision to purchase the products from the relevant zoonotically risky activities. Accordingly, this line of objection would conclude that since the policies we have proposed are paternalistic, and since it's impermissible for governments to implement paternalistic policy, then each of the policy measures we have endorsed are ultimately impermissible exercises of government power.

As an initial reply, some would dispute the normative premise in this objection; some unapologetically endorse certain forms of paternalistic justifications for public health interventions (see, esp., Conly 2012; Hanna 2019). In other words, these unabashed paternalists argue that it would be too quick to assume that because they are paternalistic, the policies we have discussed are off the table. Indeed, these paternalists would go further: to the extent that the relevant policies promote the well-being of each by being paternalistic, such policies are permissible, or even obligatory.

Nonetheless, paternalistic justifications of state intervention remain highly controversial. So, it would be worrisome if the case for intervention rested on the normative assumption that paternalism is justified more generally. But there is a different response to the charge of paternalism - one that denies the description of the policies. Even though the policies under discussion protect consumers from themselves, that is not necessarily their primary intent, nor their only intent. This is the case for a few reasons. 
First, the risks of animal agriculture only eventuate for consumers if producers continue with their current practices; the harm depends on a host of factors independent of any single individual's dietary choices. For instance, a policy that aimed to protect consumers from noncommunicable diseases that accompany overconsumption of animal products, such as heart disease, would be paternalistic, since the harm to the individual arises because of the dietary choices of the individual. In the case of zoonotic disease, by contrast, the harm to an individual is overdetermined by causal factors other than her choices - giving up animal sourced products would not, in fact, protect the consumer from the relevant harm. Since the cause of the relevant harm to a consumer of animal sourced products is overdetermined in this way, then a policy that prevents the relevant harm should not be described paternalistic. To put the same point another way, given the collective nature of the harm, the intervention should not be thought of as primarily protecting the consumer from her individual choice. By analogy, regulating how much ranchers can graze their herd in the commons does benefit the ranchers by preserving grazing land specifically by prohibiting individual ranchers from performing an action that they might otherwise like to undertake. It would be inapt to claim that such regulations are paternalistic, at least partly because the harms these ranchers impose on themselves involve a collective action problem, and the law in question solves this collective action problem rather than simply protecting the individual from her own choices.

Second, the choices of consumers and producers do not merely affect the consenting parties. Those who do not consume the products of intensive animal agriculture are also negatively impacted. Accordingly, the imposition of costs on other parties suggests that while the policies we have discussed would protect some consumers from themselves, the policies would also protect others who do not participate in the relevant risk-imposing practice - both individuals exposed to risk but do not consume the readily available products of intensive animal agriculture, and individuals exposed to risk of zoonotic disease despite living in contexts where the products of intensive animal agriculture are not nearly as available.

\section{The Least Restrictive Alternative}

A final objection draws on a widely accepted principle in public health ethics - roughly, that, out of respect for individual autonomy, governments ought to take the least restrictive means to accomplishing their public health goals (Childress et al. 2002; Nuffield Council on Bioethics 2007; Upshur 2002; Kass 2001). In the current context, some might draw on this principle to argue that, at the very least, a complete ban on intensive animal agriculture would be unjustified. They might go further and also oppose the "zoonotic tax" we have endorsed. And, to the extent that incentivizing alternative research involves taxation, the least restrictive alternative principle may count against policies that incentivize alternatives.

The extent to which this objection undermines our argument depends on two kinds of considerations. The first is conceptual: which sorts of measures should be thought of as more restrictive than others? Addressing this issue goes beyond the scope of this paper, but depending on how one resolves it, one could grant our arguments while differing over their exact policy implications.

The second kind of consideration is empirical: to what extent will different measures achieve comparable public health gains? We have given some reasons to think that a ban would be far more effective than other measures. And we have given reason to think that some measures might not be feasible - for instance, if we really wish to impose a tax to offset the negative externalities imposed by intensive animal agriculture, then it might be that the 
relevant industries will no longer be sufficiently profitable, or consumers will have to pay too much for the relevant goods. Nonetheless, we do not claim to have made such a case conclusively. Accordingly, if one can canvass evidence that measures short of a ban would be equally effective from the perspective of public health and if one accepts the least restrictive alternative requirement, then this would count in favor of the less restrictive alternatives to the ban, including a zoonotic tax.

\section{Conclusion}

We have argued that if the government has a permission to protect public health generally, then this permission extends to radically altering current animal agricultural practices. Moreover, we have done so by restricting our focus to the role that animal agriculture plays in causing communicable diseases, using the COVID-19 pandemic as a particularly striking example. We have considered several natural objections and argued that none of them undercut our arguments. While there are other objections one may raise or responses to our replies, our arguments make a powerful case for the permissibility of the different measures we discuss.

While there are urgent short-term public health measures that can mitigate the devastating effects of the COVID-19 pandemic, we must not lose sight of how to prevent the devastation of a future pandemic. When considering such measures, a natural thought is to focus on what public health agencies and local governments should do; they should be more prepared by having more tests and aggressive contact tracing, more personal protective equipment, more ventilators, or perhaps they should be prepared to institute strict social distancing measures sooner rather than later. Yet while all of these approaches are worthwhile, they are not truly preventative in that they do not address a root cause: intensive animal agriculture.

Before concluding, it's worth emphasizing how our argument fits into larger debates about the ethical issues surrounding agricultural policy.

The ethical case we make in this article is consistent with, but does not depend on, the premises of three other, perhaps more familiar, sorts of ethical arguments that often get made in the context of animal agriculture.

Many arguments about the need to reduce or eliminate intensive animal agriculture focus on harms done to animals in food production, relying on claims about animals' rights or welfare (Fischer 2019; Singer 1975; Regan 1983; Dunayer 2001; Palmer 2010; Gruen 2011). If we accept that animals have inherent rights or that animal welfare matters at least somewhat, the harms caused by intensive animal agriculture would pretty straightforwardly justify radically changing or abolishing current practices.

A second set of ethical arguments focus on environmental harms. Intensive animal agriculture is a major contributor to climate change and puts pressure on land and water use, including by contributing to local pollution (Tilman and Clark 2014; Springmann et al. 2016). As such, if one accepts any of the argument that highly environmentally impactful practices especially in wealthier countries - should be curtailed or eliminated (see, e.g., Moellendorf 2014, 2015; Caney 2010; Nolt 2011; Shue 1993, 2010; Gardiner 2004, 2006), then once again there is a powerful case for considerably curtailing, or even eliminating, intensive animal agriculture (Schlottmann and Sebo 2019).

A third class of arguments focuses on public health from the point of view of the health effects of the (over)consumption of different animal source foods and especially some types of 
meat - often in the form of noncommunicable diseases suffered by individuals - on individuals and communities (Simon 2013; Springmann et al. 2018; Stubbs et al. 2018). Yet again, if one accepts these claims, then one should support either changes in consumption patterns or some form of intervention into food production.

Those already persuaded by some or all of these arguments might wonder why this paper focuses specifically on the public health threat of animal source food production as a source of zoonotic disease risk.

Four reasons count in favor of our focus.

First, if one accepts any of the above, more common arguments for radically changing our current agricultural practices, our additional arguments only serve to further bolster these other cases.

Second, the arguments we make provide reasons for intervening in animal agriculture that one can accept even while rejecting other arguments for the same conclusion. For instance, some deny that animal welfare matters enough, or matters in the right way to warrant significant changes in animal agriculture (Lomasky 2013, 178, 192). Similarly, environmental arguments that focus on how animal agriculture contributes significantly to climate change encounter difficult questions about how much the interests or rights of future generations or the natural world should count (See, e.g., Meyer 2020). And, as we have seen, many would reject a broadly paternalistic argument that focuses on how overconsumption increases noncommunicable disease burden because they reject such paternalistic rationales more generally (Flanigan 2014b; Quong 2011; Mill 1869). The argument we make, however, does not rest on claims about the moral significance of animal welfare, the moral significance of future people or nonhuman nature, and we offer arguments that proponents and opponents of paternalism can consistently accept.

Third, and relatedly, the public health case we make straightforwardly justifies government action in a way that some of these other arguments do not. Many claim that government is especially well-suited, or perhaps uniquely suited, to take action in order to address other public health threats that are structurally similar to those imposed by intensive animal agriculture. In other words, by viewing this problem through the lens of public health ethics, we suggest that the justificatory case for government intervention becomes especially strong.

Fourth, and finally, there is a sense in which an argument that focuses on the risks of zoonotic disease may be more persuasive to the public than these other arguments. We're notoriously bad at changing our diets in the name of self-interest, perhaps due to our difficulty with delayed gratification. Many appear to be unconcerned by the welfare of the animals they eat. And, so far, appealing to the connection between intensive animal agriculture and climate change has left many people unmoved. The threat of another pandemic, by contrast, may be the right kind of consideration to motivate people to seriously re-examine our current dietary practices, especially when we've witnessed firsthand just how devastating a pandemic can be.

The risk of infectious disease associated with animal agriculture is often overlooked. The COVID-19 pandemic forces us to pay attention to food production and evaluate how to reduce similar outbreaks in the future in the interest of global, collective public health. While the exact causes of this particular pandemic still require further investigation, we have highlighted the causal role of intensive animal agriculture in other pandemics and its contribution to increased risk of future zoonotic disease outbreaks. Accordingly, it is worth drawing on the costs and harms associated with the current pandemic so as to help the public understand the public health case for restricting or eliminating intensive animal agriculture so as to prevent similar harms and costs in the future. 
Acknowledgments For helpful comments on earlier drafts, the authors would like to thank Raj N. Patel, Dylan Manson, Pierce Randall, and Ruth Faden. Jan Dutkiewicz is grateful for the support of the Swiss National Science Foundation through a Sinergia grant and of the Social Sciences and Humanities Research Council of Canada through a Partnership Engage grant. Dutkiewicz completed work on this article during his time as a Policy Fellow at Harvard Law School's Animal Law and Policy Program. The authors are also very appreciative of the detailed and generative feedback provided by the two anonymous reviewers.

\section{Declarations}

Conflict of Interest On behalf of all authors, the corresponding author states that there is no conflict of interest.

\section{References}

Akhtar, A., M. Greger, H. Ferdowsian, and E. Frank. 2009. Health professionals' roles in animal agriculture, climate change, and human health. American Journal of Preventive Medicine 36: 182-187. https://doi.org/ 10.1016/j.amepre.2008.09.043.

Ambasta, A., and J. Buonocore. 2018. Carbon pricing: A win-win environmental and public health policy. Canadian Journal of Public Health 109: 779-781.

Anomaly, J. 2009. Harms to others: The social costs of antibiotics in agriculture. Journal of Agricultural and Environmental Ethics 22: 423-435.

Anomaly, J. 2011. Public health and public goods. Public Health Ethics 4 (3): 251-259.

Benatar, D. 2007. The chickens come home to roost. American Journal of Public Health 97 (9): 1545-1546. https://doi.org/10.2105/AJPH.2006.090431.

Bernstein, J., and P. Randall. 2020. Against the public goods conception of public health. Public Health Ethics 13 (3): 225-233. https://doi.org/10.1093/phe/phaa021.

Berson, J. 2019. The meat question. Cambridge, MA: MIT Press.

Bonnet, C., Z. Bouamra-Mechemeche, V. Requillart, and N. Treich. 2020. Regulating meat consumption: How to improve health, the environment and animal welfare. Food Policy. https://doi.org/10.1016/j.foodpol.2020. 101847.

Braveman, P., C. Cubbin, S. Egerter, D. Williams, and E. Pamuk. 2010. Socioeconomic disparities in health in the United States: What the patterns tell us. American Journal of Public Health 100 (S1): 186-196.

Brennan, J. 2018. A libertarian case for mandatory vaccination. Journal of Medical Ethics 44: 37-43.

Caney, S. 2010. Climate change, human rights, and moral thresholds. In Human rights and climate change, ed. S. Humphreys, 69-90. Cambridge: Cambridge University Press.

Childress, J. F., R. R. Faden, R. D. Gaare, L. O. Gostin, J. Kahn, R. J. Bonnie, N. E. Kass, A. C. Mastroianni, J. D. Moreno, and P. Nieburg. 2002. Public health ethics: Mapping the terrain. The Journal of Law, Medicine \& Ethics 30 (2): 170-178.

Coker R et al (2011) Towards a conceptual framework to support one-health research for policy on emerging zoonoses. Lancet Infect Dis 11: 326-331

Conly, S. 2012. Against autonomy: Justifying coercive paternalism. New York: Cambridge University Press.

Cutler, D.M., and L.H. Summers. 2020. The COVID-19 pandemic and the \$16 trillion virus. Journal of the American Medical Association. 324 (15): 1495-1496.

Daniels, N. 2008. Just health: Meeting health needs fairly. New York: Cambridge University Press.

Daszak, P., A.A. Cunningham, and A.D. Hyatt. 2000. Emerging infectious diseases of wildlife-Threats to biodiversity and human health. Science 287: 443-449.

Dees, R.H. 2018. Public health and normative public goods. Public health ethics 11 (1): 20-26.

Dunayer, J. 2001. Animal equality. New York: Lantern Books.

Dutkiewicz, J. 2020. Uncertain hog futures: Life, death, and arbitrage on the factory farm. Journal of Cultural Economy 13 (3): 278-289.

Dworkin, G. 2020. Paternalism. In The Stanford encyclopedia of philosophy (fall 2020 edition), ed. E.N. Zalta. Available from: https://plato.stanford.edu/archives/sum2020/entries/paternalism/.

Espinosa, R., D. Tago, and N. Treich. 2020. Infectious diseases and meat production. Environmental and Resource Economics. 76: 1019-1044.

Faden, R., S. Shebaya, and A. Siegel. 2019. Public health programs and policies: Ethical justifications. In The Oxford handbook of public health ethics, ed. A.C. Mastroianni, J.P. Kahn, and N.E. Kass, 21-32. New York: Oxford University Press. 
Faden, Ruth R. 2020. What's at stake when schools close for the coronavirus? A bioethicist weighs. In Education week. Available from https://www.edweek.org/leadership/opinion-whats-at-stake-when-schools-close-forthe-coronavirus-a-bioethicist-weighs-in/2020/03.

Faden, Ruth R., J. Bernstein, and S. Shebaya. 2020. Public health ethics. In E.N. Zalta, ed. The Stanford encyclopedia of philosophy (Fall 2020 edition) Available from: https://plato.stanford.edu/entries/ publichealth-ethics/.

FAO. 2019. Meat market review, march 2019. Rome: Food and Agriculture Organization.

Fischer, B. 2019. The ethics of eating animals: Usually bad, sometimes wrong, and often permissible. New York: Routledge Press.

Fitzgerald, A. 2010. A social history of the slaughterhouse. Human Ecol Forum. 17 (1): 58-69.

Flanigan, J. 2014a. A defense of compulsory vaccination. HEC Forum 26: 5-25.

Flanigan, J. 2014b. The perils of public health regulations. Society 51: 229-236.

Galvin, R., and N. Healy. 2020. The green new Deal in the United States: What is it and how to pay for it. Energy Research \& Social Science. https://doi.org/10.1016/j.erss.2020.101529.

Gardiner, S.M. 2004. Ethics and global climate change. Ethics 114: 555-600.

Gardiner, S.M. 2006. A core precautionary principle. Journal of Political Philosophy 14: 33-60.

Gaus, G.F. 2011. The order of public reason: A theory of freedom and morality in a diverse and bounded world. New York: Cambridge University Press.

Gaus, G.F. 1999. Social philosophy. London: M.E. Sharpe Publishing.

Gilchrist, M.J., et al. 2007. The potential role of concentrated animal feeding operations in infectious disease epidemics and antibiotic resistance. Environmental Health Perspectives 115 (2): 313-316.

Giubilini, A. 2019a. The ethics of vaccination. Palgrave Macmillan.

Giubilini, A. 2019b. An argument for compulsory vaccination: The taxation analogy. Journal of applied philosophy. https://doi.org/10.1111/japp.12400.

Godfray, H.C.J., et al. 2018. Meat consumption, health, and the environment. Science 361: eaam5324.

Graham, J.P., et al. 2008. The animal-human interface and infectious disease in industrial food animal production: Rethinking biosecurity and biocontainment. Public Health Reports 123 (3): 282-299.

Grill, K., and K. Voigt. 2016. The case for banning cigarettes. Journal of Medical Ethics 42: 293-301.

Gruen, L. 2011. Ethics and animals. New York: Cambridge University Press.

Hanna, J. 2019. In our best interest: A defense of paternalism. New York: Oxford University Press.

Hansen, P.G., Schilling, M., and Malthesen M.S. 2019. Nudging healthy and sustainable food choices: three randomized controlled field experiments using a vegetarian lunch-default as a normative signal. J Public Health. https://doi.org/10.1093/pubmed/fdz154.

Hansson, S. 2018. Risk. In E.N. Zalta, ed. The Stanford encyclopedia of philosophy (Fall 2018 edition) Available from https://plato.stanford.edu/archives/fall2018/entries/risk/.

Hirvonen, K., Y. Bai, D. Headey, and W.A. Masters. 2020. Affordability of the EAT-lancet reference diet: A global analysis. The Lancet Global Health. 8 (1): e59-e66.

Holland, S. 2007. Public health ethics. Cambridge: Polity Press.

Hopkins, P., and A. Dacey. 2008. Vegetarian meat: Could technology save animals and satisfy meat eaters? Journal of Agricultural and Environmental Ethics 21 (6): 579-596.

Horne, L. Chad. 2019. Public health, public goods, and market failure. Public health ethics 12 (3): $287-292$.

Jakobsen, J., and A. Hansen. 2020. Geographies of meatification: An emerging Asian meat complex. Globalizations 17 (1): 93-109. https://doi.org/10.1080/14747731.2019.1614723.

Jones, B.A., D. Grace, R. Kock, et al. 2013. Zoonosis emergence linked to agricultural intensification and environmental change. Proceedings of the National Academy of Sciences of the United States of America 110 (21): 8399-8404. https://doi.org/10.1073/pnas.1208059110.

Jones, K.E., et al. 2008. Global trends in emerging infectious diseases. Nature 451 (7181): 990-993.

Jones, M.M., and R. Bayer. 2007. Paternalism and its discontents. The American Journal of Public Health 97 (2): 208-217.

Kass, N. 2001. An ethics framework for public health. American Journal of Public Health 91 (11): 1776-1782.

Katare, B., H.H. Wang, J. Lawing, N. Hao, T. Park, and M. Wetzstein. 2020. Toward optimal meat consumption. American Journal of Agricultural Economics. 102: 662-680.

Lomasky, L. 2013. Is it wrong to eat animals? Social Philosophy and Policy 30: 177-200.

Lopez, M.H., R. Lee, and A. Budiman. 2020. Financial and health impacts of COVID-19 vary widely by race and ethnicity. Pew Research Center 5: 2020. Accessed 10 June 2020. Available at: https://www. pewresearch.org/fact-tank/2020/05/05/financial-and-health-impacts-of-covid-19-vary-widely-by-raceandethnicity/.

Mack, E. (2015) Elbow room for rights. In Oxford studies in political philosophy, ed. D. Sobel, P. Vallentyne, and S. Wall, vol. 1. Oxford: Oxford University Press. 
Meyer, L. 2020. Intergenerational justice. In The Stanford encyclopedia of philosophy (summer 2020 edition)., ed. E.N. Zalta https://plato.stanford.edu/archives/sum2020/entries/justice-intergenerational/.

Middleton, J., R. Ralf, and L. Henrique. 2020. Meat plants-A new front line in the covid-19 pandemic. BMJ. 370: $\mathrm{m} 2716$.

Mill, J.S. 1869. On liberty \& other essays (2nd edition.). ed. J. Gray, vol. 1998. New York: Oxford University Press.

Moellendorf, D. 2014. The moral challenge of dangerous climate change: Values, policy, and poverty. Cambridge: Cambridge University Press.

Moellendorf, D. 2015. Climate change justice. Philosophy Compass 10 (3): 173-186.

Navin, M. 2016. Values and vaccine refusal: Hard questions in ethics, epistemology, and health. New York: Routledge Press.

Nolt, J. 2011. Greenhouse gas emission and the domination of posterity. In The ethics of global climate change, ed. Denis Arnold, 60-76. Cambridge: Cambridge University Press.

Nozick, R. 1974. Anarchy, state, and utopia. New York: Basic Books.

Nuffield Council on Bioethics. 2007. Public health: Ethical issues. Cambridge: Cambridge Publishers.

Nussbaum, M. 2006. Frontiers of justice: Disability, nationality, species membership. Cambridge.

Nussbaum, M. 2011. Creating capabilities. Cambridge: Harvard University Press. https://doi.org/10.1007/ s41055-021-00089-6.

Organisation for Economic Cooperation and Development (OECD). 2020. "Evaluating the initial impact of COVID-19 measures on economic activity". Accessed 31 Dec 2020. http://www.oecd.org/coronavirus/ policy-responses/evaluating-the-initial-impact-of-covid-19-containment-measures-on-economic-activityb1f6b68b/

Pal, M., S. Tesfaye, and P. Dave. 2013. Zoonoses occupationally acquired by abattoir workers. Journal of Environmental and Occupational Science 2: 155-162. https://doi.org/10.5455/jeos.20131013121517.

Palmer, Clare. 2010. Animal ethics in context. New York: Columbia University Press.

Parker, K., J. M. Horowitz, and A. Brown. 2020. About half of lower-income Americans report household job or wage loss due to covid-19. Pew Research Center. Accessed June 10, 2020. Available at: https://www. pewsocialtrends.org/2020/04/21/about-half-of-lower-income-americans-report-household-job-or-wagelossdue-to-covid-19/.

Patz, J.A., et al. 2004. Unhealthy landscapes: Policy recommendations on land use change and infectious disease emergence. Environmental Health Perspectives 112 (10): 1092-1098. https://doi.org/10.1289/ehp.6877.

Pigou, A. 2013. The economics of welfare. London: Palgrave Macmillan [1920].

Pomeranz, J. 2012. Advanced policy options to regulate sugar-sweetened beverages to support public health. Journal of Public Health Policy 33 (1): 75-88.

Powers, M., and R. Faden. 2019. Structural injustice: Power, advantage, and human rights. New York: Oxford University Press.

Powers, M., and R. Faden. 2006. Social justice. New York: Oxford University Press.

Quong, J. 2011. Liberalism without perfection. New York: Oxford University Press.

Rawls, J. 1999. A theory of justice. Revised ed. Harvard: Harvard University Press.

Regan, T. 1983. The case for animal rights. Berkeley: The University of California Press.

Rohr, J., et al. 2019. Emerging human infectious diseases and the links to global food production. Nature Sustainability 2 (6): 445-456.

Ruger, J.P. 2010. Health and social justice. New York: Oxford University Press.

Säll, S., and I.M. Gren. 2015. Effects of an environmental tax on meat and dairy consumption in Sweden. Food Policy 55: 41-53.

Santo, R., et al. 2020. Considering plant-based meat substitutes and cell-based meats: A public health and food system perspective. Frontiers in Sustainable Food Systems. 4: 134. https://doi.org/10.3389/fsufs.2020. 00134.

Schlottmann, C., and J. Sebo. 2019. Food, animals, and the environment: An ethical approach. New York: Routledge.

Schneider, M. 2017. Wasting the rural: Meat, manure, and the politics of agro-industrialization in contemporary China.

Sen, A. 1999. Development as freedom. New York: Knopf.

Sen, A. 2009. The idea of justice. London: Allen Lane.

Shue, H. 1993. Subsistence emissions and luxury emissions. Law \& Policy 15: 39-59.

Shue, H. 2010. Deadly delays, saving opportunities: Creating a more dangerous world? In Climate ethics: Essential readings, ed. S.M. Gardiner et al., 146-162. Oxford: Oxford University Press.

Simon, D.R. 2013. Meatonomics: How the rigged economics of meat and dairy make you consume too muchand how to eat better, live longer, and spend smarter. San Francisco: Conari Press.

Singer, P. 1975. Animal liberation. New York: Harper Perennial 2009. 
Sinnott-Armstrong, W. 2005. "It's not my fault!" in Perspectives on climate change: Science, economics, politics, ethics. ed. W. Sinnott-Armstrong and R.B. Howarth. Bingley, UK: Emerald Group Publishing Limited: 293-315.

Smolinski, M.S., M.A. Hamburg, and J. Lederberg. 2003. Microbial threats to health: emergence, detection, and response. Washington and the committee on emerging microbial threats to health in the 21 st century: National Academies Press.

Springbett, A.J., K. MacKenzie, J.A. Woolliams, and S.C. Bishop. 2003. The contribution of genetic diversity to the spread of infectious diseases in livestock populations. Genetics 165 (3): 1465-1474.

Springmann, M., H.C. Godfray, M. Rayner, and P. Scarborough. 2016. Analysis and valuation of the health and climate change cobenefits of dietary change. Proceedings of the National Academy of Sciences 113: 4146-4151.

Springmann, M., D. Mason-D’Croz, S. Robinson, W. Keith, H. Charles, J. Godfray, M. Rayner, and P. Scarborough. 2018. Health-motivated taxes on red and processed meat: A modelling study on optimal tax levels and associated health impacts. PLoS One: e0204139. https://doi.org/10.1371/journal.pone.0204139.

Stephens, N., A.E. Sexton, and C. Driessen. 2019. Making sense of making meat: Key moments in the first 20 years of tissue engineering muscle to make food. Frontiers in Sustainable Food Systems 3: 45. https:/doi. org/10.3389/fsufs.2019.00045.

Stewart, E. 2020. Essential workers are taking care of America. Are we taking care of them? Vox. Accessed June 10, 2020. https://www.vox.com/covid-19-coronavirus-explainers/2020/4/23/21228971/essential-workersstories-coronavirus-hazard-pay-stimulus-covid-19.

Stubbs, R.J., S.E. Scott, and C. Duarte. 2018. Responding to food, environment and health challenges by changing meat consumption behaviours in consumers. Nutrition Bulletin 43 (2): 125-134.

The New York Times. 2020. 50 million kids can't attend school. What happens to them? April 16. https://www. nytimes.com/2020/04/16/opinion/coronavirus-schools-closed.html?referringSource=articleShare.

Tilman, D., and M. Clark. 2014. Global diets link environmental sustainability and human health. Nature 515: $518-522$.

UNEP. 2016. UNEP frontiers 2016 report: Emerging issues of environmental concern. Nairobi: United Nations Environment Programme.

Upshur, R. 2002. Principles for the justification of public health intervention. Canadian Journal of Public Health 93 (2): 101-103.

Van Dorn, A., et al. 2020. COVID-19 exacerbating inequalities in the US. Lancet. 395 (10232): 1243-1244.

Viscusi, W. Kip. 1995. Cigarette taxation and the social consequences of smoking. Tax Policy and the Economy 9: 51-101.

Wadhera, R.K., P. Wadhera, and P. Gaba. 2020. Variation in COVID-19 hospitalizations and deaths across New York City boroughs. Journal of the American Medical Association. Accessed (10 June 2020). https:// jamanetwork.com/journals/jama/article-abstract/2765524.

Weis, T. 2013. The ecological hoofprint. Zed Books.

Willet, W., Rockström, J., Loken, B., Springman, M., Lang, T., Vermeulen, S., et al. 2019. Food in the anthropocene: the EAT-Lancet Commission on healthy diets from sustainable food systems, The Lancet, 393 (February 2): 447-492.

World Health Organization. 2021. WHO coronavirus disease (COVID-19) dashboard. Accessed 1 Jan 2021 https://covid19.who.int/

Publisher's Note Springer Nature remains neutral with regard to jurisdictional claims in published maps and institutional affiliations.

\section{Affiliations}

\section{Justin Bernstein ${ }^{1}$ • Jan Dutkiewicz ${ }^{2}$}

1 Department of Philosophy, Florida Atlantic University, 777 Glades Road - SO 283, Boca Raton, FL 334310991, USA

2 Department of Sociology and Anthropology, Concordia University, 1455 de Maisonneuve Blvd. West, Montréal, QC H2G 1M8, Canada 